\title{
Detailed Photoisomerization Dynamics of a Green Fluorescent Protein Chromophore Based Molecular Switch
}

\author{
Chen-Wei Jiang, ${ }^{1}$ Ai-Ping Fang, ${ }^{1}$ Di Zhao, ${ }^{1}$ Hong-Rong Li, ${ }^{1}$ Rui-Hua Xie, ${ }^{1,2}$ and Fu-Li Li ${ }^{1}$ \\ ${ }^{1}$ MOE Key Laboratory for Nonequilibrium Synthesis and Modulation of Condensed Matter and Department of Applied Physics, \\ Xian Jiaotong University, Xi'an 710049, China \\ ${ }^{2}$ Department of Physics, Hubei University, Wuhan 430062, China
}

Correspondence should be addressed to Chen-Wei Jiang; jiangcw@mail.xjtu.edu.cn and Fu-Li Li; flli@mail.xjtu.edu.cn

Received 25 April 2014; Accepted 16 July 2014; Published 3 September 2014

Academic Editor: Yusheng Dou

Copyright (C) 2014 Chen-Wei Jiang et al. This is an open access article distributed under the Creative Commons Attribution License, which permits unrestricted use, distribution, and reproduction in any medium, provided the original work is properly cited.

\begin{abstract}
With density-functional-based nonadiabatic molecular dynamics simulations, trans-to-cis and cis-to-trans photoisomerizations of a green fluorescent protein chromophore based molecule 4-benzylidene-2-methyloxazol-5(4H)-one (BMH) induced by the excitation to its $S_{1}$ excited state were performed. We find a quantum yield of $32 \%$ for the trans-to-cis photoisomerization of $\mathrm{BMH}$ and a quantum yield of $33 \%$ for its cis-to-trans photoisomerization. For those simulations that did produce trans-to-cis isomerization, the average $S_{1}$ excited state lifetime of trans-BMH is about $1460 \mathrm{fs}$, which is much shorter than that of cis-BMH ( $\left.3100 \mathrm{fs}\right)$ in those simulations that did produce cis-to-trans isomerization. For both photoisomerization processes, rotation around the central C2=C3 bond is the dominant reaction mechanism. Deexcitation occurs at an avoided crossing near the $S_{1} / S_{0}$ conical intersection, which is near the midpoint of the rotation.
\end{abstract}

\section{Introduction}

Molecules with the ability to undergo photoisomerization under radiation would have potential applications in molecular switches and other molecular devices. Photoisomerization mechanisms of stilbene [1-3], fulgide [4-6], diarylethene [7-9], and azobenzene [10-14], together with their derivatives [15-19], have been widely studied during the last two decades. Despite their appealing features as effective molecular switches, azobenzene derivatives and above photochromic compounds are just examples of a whole family of compounds capable of performing controlled isomerization reactions. The discovery of new or alternative photoswitch types could expand the applicability of the switch concept to different and increasingly complex molecular environments.

The chromophore of the green fluorescent protein, as a biomolecule from jellyfish Aequorea victoria, has been widely used as a genetically encoded noninvasive fluorescence marker in bioimaging [20]. Recently, several studies have revealed that the green fluorescent protein chromophore and its different modifications undergo photo-induced Z/E isomerization under radiation [21-26], which offer them the opportunity to be molecular switches. Through investigation of several spectral modification of synthetic chromophore analogues of wild-type green fluorescent protein, Voliani et al. [21] found that cis-to-trans photoisomerization should be a general mechanism of green fluorescent protein chromophores whose efficiency can be modulated by the detailed mutant-specific protein environment. Using femtosecond fluorescence upconversion spectroscopy and quantum chemical calculations, Rafiq et al. [22] investigated two green fluorescent protein chromophore analogs and proposed a multicoordinate relaxation mechanism. Oxazolone analogs, as well-known intermediates in the synthesis of green fluorescent protein derivatives, have attracted relatively little attention in terms of their photoswitching ability. Very recently, several oxazolone analogs of the green fluorescent protein chromophore were synthesized and predicted to be good candidates for molecular switches by Blanco-Lomas et al. [27].

To furnish a deeper and detailed mechanistic understanding of the photoisomerization reaction of those green fluorescent protein chromophore based molecular switches, semiclassical nonadiabatic molecular dynamics simulations were 
performed for a molecule 4-benzylidene-2-methyloxazol$5(4 \mathrm{H})$-one $(\mathrm{BMH}$, named as $2 \mathrm{e}$ in [27]) in our group. We found that the average lifetime of the $S_{1}$ excited state in trans$\mathrm{BMH}$ is about $1450 \mathrm{fs}$, much shorter than that of cis-BMH ( $3100 \mathrm{fs}$ ), which is in good agreement with the experimental result [27].

This paper is organized as follows. Our semiclassical nonadiabatic molecular dynamics simulation method is briefly reviewed in Section 2. The detailed results and discussions are represented in Section 3, followed by a conclusion in Section 4.

\section{Methodology}

Our nonadiabatic molecular dynamics simulation method was named semiclassical electron-radiation-ion dynamics (SERID), which has been described in detail elsewhere [28, 29]. We only briefly review it under below.

To obtain the evolution equations of electrons and nuclei, we postulate a mixed classical-quantum action [30-32] $S=$ $\int d t L$, where

$$
\begin{aligned}
L= & \frac{1}{2}\left\langle\Psi_{e}\left|\left(i \hbar \frac{\partial}{\partial t}-\mathscr{H}_{e}\right)\right| \Psi_{e}\right\rangle+\text { h.c. } \\
& +\frac{1}{2} \sum_{k \alpha} M_{k}\left(\frac{d X_{k \alpha}}{d t}\right)^{2}-U_{\text {rep }} .
\end{aligned}
$$

$\mathscr{H}_{e}$ is the electronic Hamiltonian, $\left|\Psi_{e}\right\rangle$ is the electronic state, "h.c." means "Hermitian conjugate," $k$ labels a nucleus with spatial coordinates $\alpha$, and $U_{\text {rep }}$ is the repulsive interaction between nuclei and ion cores. As shown in [32], if one makes the usual time-dependent effective-field approximation and employs a nonorthogonal basis, extremalization of this action leads to the time-dependent Schrödinger equation:

$$
i \hbar \frac{\partial}{\partial t} \boldsymbol{\psi}(t)=\mathbf{S}^{-1} \cdot \mathbf{H} \cdot \boldsymbol{\psi}(t)
$$

and to the equation of motion for the nuclei

$$
\begin{aligned}
M \frac{d^{2} X}{d t^{2}}= & -\frac{1}{2} \sum_{n} \psi_{n}^{\dagger} \cdot\left(\frac{\partial \mathbf{H}}{\partial X}-i \hbar \frac{\partial \mathbf{S}}{\partial X} \frac{\partial}{\partial t}\right) \cdot \psi_{n} \\
& + \text { h.c. }-\frac{\partial U_{\text {rep }}}{\partial X} .
\end{aligned}
$$

The Hamiltonian matrix $\mathbf{H}$, overlap matrix $\mathbf{S}$, and repulsive potential $U_{\text {rep }}$ are obtained from the density-functionalbased parameterizations of Frauenheim and coworkers [33, 34].

The results of $[14,35-44]$ calculated with SERID method have provided a clear demonstration of the following features of simulations based on Ehrenfest dynamics: (1) electronic transitions are automatically observed at an avoided crossing near a conical intersection in configuration space predicted by Teller $[45,46]$, with energy released to molecular vibrations; (2) these transitions occur rapidly, over a time interval of $\sim 2$ femtosecond, during which the nuclei do not move appreciably.
TABLE 1: Optimized geometrical parameters of cis-BMH and trans$\mathrm{BMH}$, calculated with our SERID method and B3LYP/6-311G(d,p) implemented in Gaussian 03 software package. The lengths are in $\AA$ and the dihedral angles and bond angles are in degrees.

\begin{tabular}{lcc}
\hline & SERID & B3LYP/6-311G(d,p) \\
\hline cis & & \\
C1C2C3C6 & 180.0 & 180.0 \\
C3C2C1C5 & 0.0 & 0.0 \\
C1C2H12C3 & 180.0 & 180.0 \\
C1C2C3 & 127.0 & 129.9 \\
C2C1C5 & 122.9 & 123.5 \\
C2C3N21 & 127.6 & 129.4 \\
C2-C3 & 1.37 & 1.35 \\
C1-C2 & 1.45 & 1.45 \\
C3-N21 & 1.42 & 1.40 \\
trans & & \\
C1C2C3C6 & 0.1 & 0.0 \\
C3C2C1C5 & 0.1 & 0.0 \\
C1C2H12C3 & 180.0 & 180.0 \\
C1C2C3 & 130.8 & 134.3 \\
C2C1C5 & 124.6 & 125.4 \\
C2C3N21 & 119.0 & 120.3 \\
C2-C3 & 1.37 & 1.36 \\
C1-C2 & 1.45 & 1.45 \\
C3-N21 & 1.43 & 1.41 \\
\hline
\end{tabular}

In the present work, we have made a little change in the procedure that should lead to better results for the quantum yields. By simply placing an electron in the lowest unoccupied molecular orbital (LUMO) and a hole in the highest occupied molecular orbital (HOMO) in the beginning of nonadiabatic simulations, we focus exclusively on the $S_{0}-S_{1}$ excitation, as in other excited state molecular dynamics simulations $[47,48]$. However, we still allow deexcitation to occur automatically at an avoided crossing near a conical intersection, since we found that deexcitation was already nearly complete in our present simulations.

\section{Results and Discussion}

We optimized the cis and trans structures of $\mathrm{BMH}$ in the ground state, starting from $300 \mathrm{~K}$ through reducing the nuclear velocities by a factor of 0.9997 after each time step of $0.01 \mathrm{fs}$ until the total molecular kinetic energy was less than $10^{-7} \mathrm{eV}$. The optimized geometries of cis and trans $\mathrm{BMH}$ are presented in Figure 1, with their geometrical parameters summarized in Table 1 . We also optimized both structures with B3LYP/6-311G(d,p) implemented in Gaussian 03 software package [49]. Both results are in good agreement with each other. The electronic energy of cis-BMH is $0.11 \mathrm{eV}$ lower than that of trans-BMH in our SERID calculation, agreeing well with the energy difference $(0.13 \mathrm{eV})$ obtained with B3LYP/6-311G(d,p) method. Both results confirm that cis-BMH is more stable than its trans isomer. Starting from its optimized geometry, each molecule was then heated to $300 \mathrm{~K}$ 


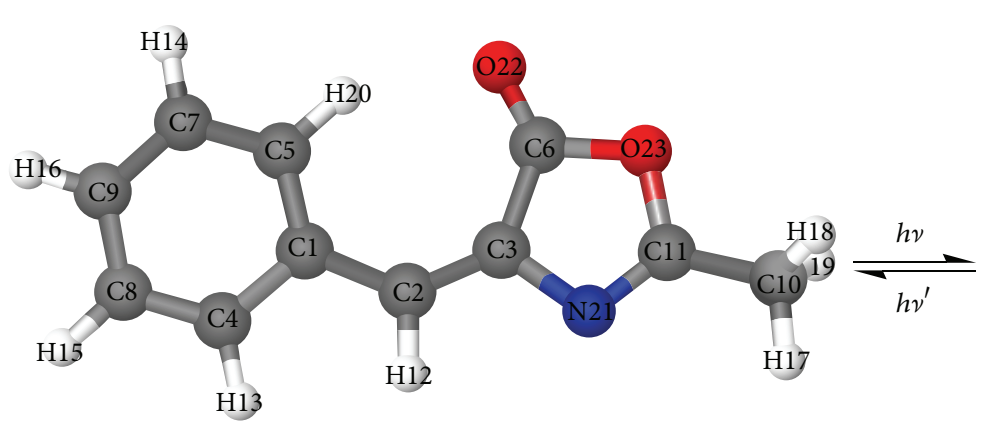

(a)

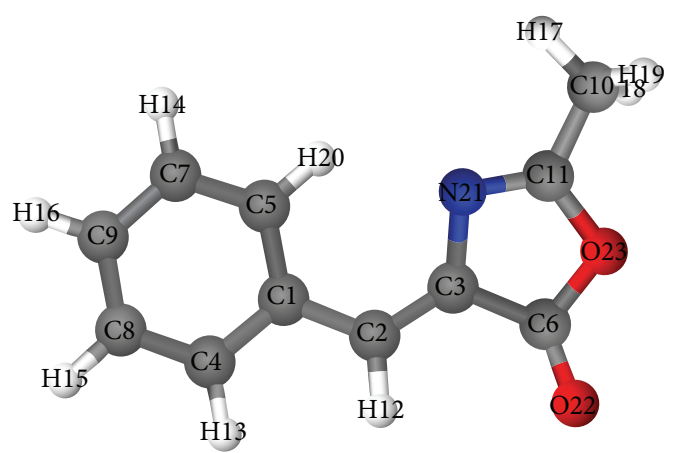

(b)

FIGURE 1: Optimized geometries of (a) trans and (b) cis structures of BMH calculated with SERID. All atoms are labelled.

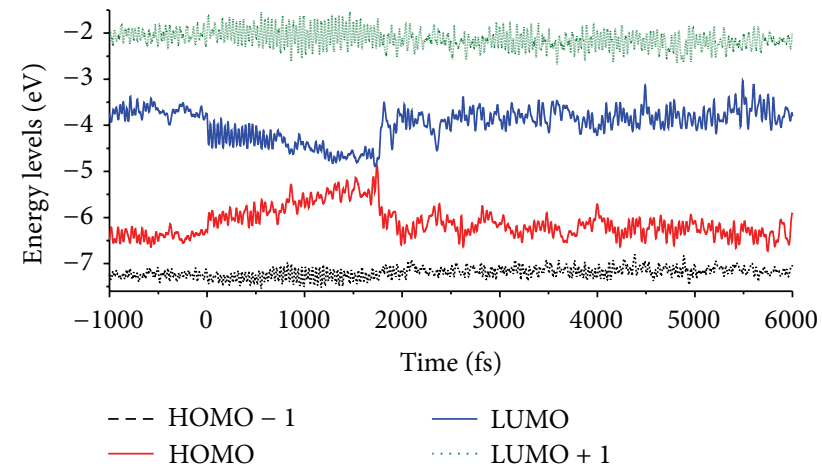

(a)

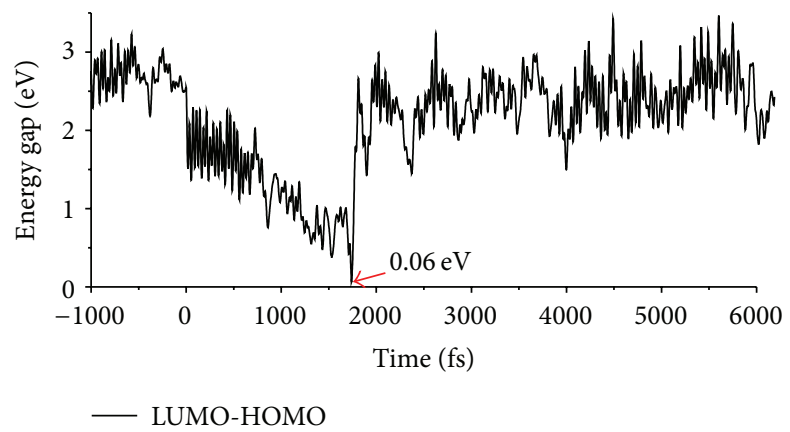

(b)

Figure 2: Time dependence of (a) orbital energies from HOMO - 1 to LUMO + 1 and (b) LUMO-HOMO energy gap in BMH for the trans-to-cis isomerization. $0.06 \mathrm{eV}$ is the minimum value of the LUMO-HOMO energy gap in this simulation.

(via random velocities resulting in this temperature) and then allowed to equilibrate and move in the electronic ground state for $10000 \mathrm{fs}$. The initial conditions for various simulations were then sampled from the configurations during the last half of this $10000 \mathrm{fs}$ interval.

3.1. trans-to-cis Photoisomerization of BMH. Starting from the first excited state of trans-BMH with different initial conditions, 90 simulations have been performed, 29 of which resulted in trans-to-cis isomerization. So the quantum yield of this reaction in our calculation is about $32 \%$. For the 29 simulations which did produce trans-to-cis isomerization, the average $S_{1}$ lifetime of trans-BMH is about $1460 \mathrm{fs}$. A detailed discussion of the isomerization mechanism in a representative simulation with a $1740 \mathrm{fs} S_{1}$ lifetime is presented below.

$\mathrm{BMH}$ molecule is excited to the $S_{1}$ excited state at time $t=0 \mathrm{fs}$. To compare the results before and after the excitation, the results before $0 \mathrm{fs}$ are also presented in Figures 2-7 below. Time dependence of the four orbital energies nearest the initial HOMO-LUMO gap are displayed in Figure 2. As we can see, after the excitation at $0 \mathrm{fs}$, only the HOMO and LUMO energy levels are affected evidently. The energy gap between HOMO and LUMO orbitals, as shown in Figure 2(b), decreases continuously from $2.55 \mathrm{eV}$ to $0.06 \mathrm{eV}$ until $1739 \mathrm{fs}$.
After about $1810 \mathrm{fs}$, the energy gap between $\mathrm{HOMO}$ and LUMO returns to about $2.66 \mathrm{eV}$ and then vibrates around this new value until the end of our simulation. Electron occupations for the four orbitals presented in Figure 2(a) after the excitation are shown in Figure 3. As we can see, BMH deexcites to its ground state at about $1740 \mathrm{fs}$ in $4 \mathrm{fs}$ interval; nearly all electrons return to their ground state. The lifetime of the $S_{1}$ excited state in trans-BMH is thus about $1740 \mathrm{fs}$.

Variations of geometry for $\mathrm{BMH}$ are displayed in Figures 4-7. As displayed in Figure 4, dihedral angle $\mathrm{C} 1 \mathrm{C} 2 \mathrm{C} 3 \mathrm{C} 6$ vibrates around $0^{\circ}$ before the excitation at $0 \mathrm{fs}$, after the excitation, which increases continuously from $-27^{\circ}$ to about $73^{\circ}$ at $1740 \mathrm{fs}$ when $\mathrm{BMH}$ returns to the ground state. After the deexcitation at $1740 \mathrm{fs}$, the rotation around $\mathrm{C} 2=\mathrm{C} 3$ bond continues. Dihedral angle C1C2C3C6 reaches $180^{\circ}$ (the optimized value for dihedral angle $\mathrm{C} 1 \mathrm{C} 2 \mathrm{C} 3 \mathrm{C} 6$ in cis-BMH) at about $2040 \mathrm{fs}$ and then vibrates around this new value, which can demonstrate that the molecule arrives at its cis geometry in about $2040 \mathrm{fs}$. Atomic distance between H20 and N21 displayed in Figure 7(c) can be another confirmation for the final cis geometry. After the excitation at $0 \mathrm{fs}$, the distance between $\mathrm{H} 20$ and $\mathrm{N} 21$ decreases continuously from about $4.4 \AA$ to $2.2 \AA$ until $2040 \mathrm{fs}$ and then vibrates around this value until the end of our simulation. Other two dihedral 


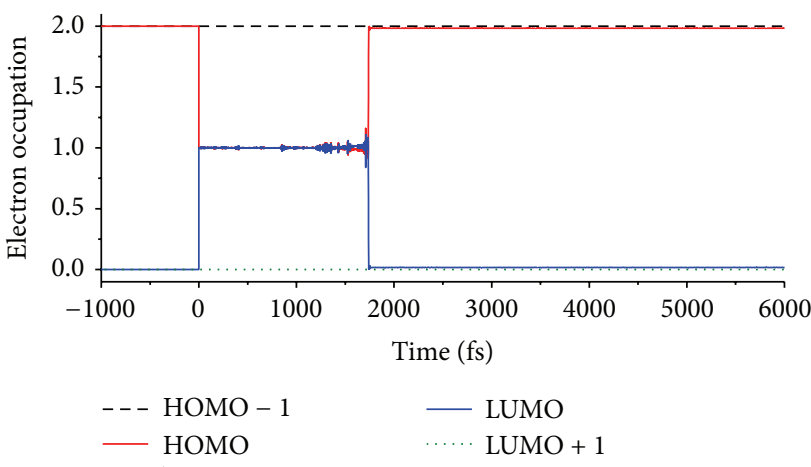

(a)

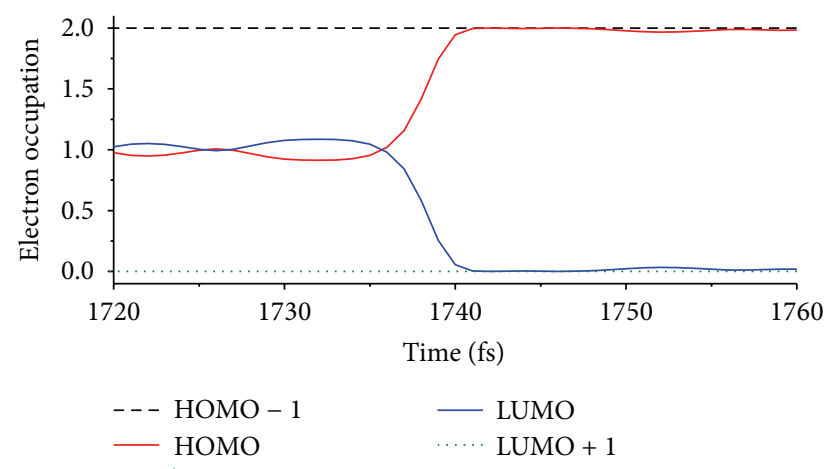

(b)

Figure 3: (a) Evolution of electron occupations in BMH from HOMO - 1 to LUMO + 1 for the trans-to-cis isomerization. (b) Details of Figure 3(a) from 1720 to $1760 \mathrm{fs}$.

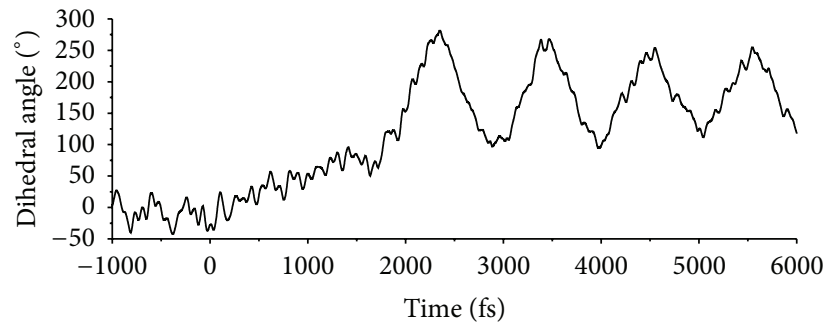

$-\mathrm{C} 1 \mathrm{C} 2 \mathrm{C} 3 \mathrm{C} 6$

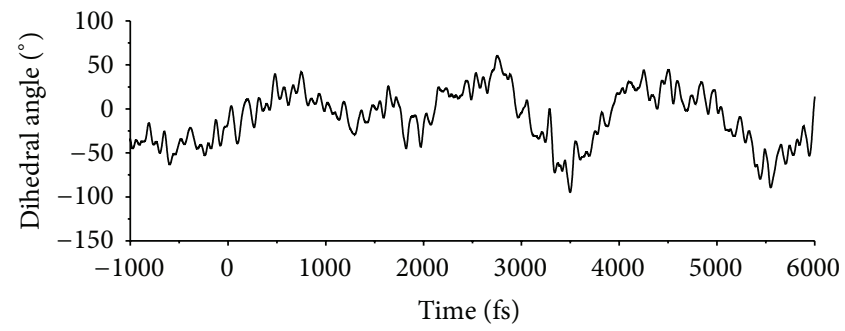

$-\mathrm{C} 3 \mathrm{C} 2 \mathrm{C} 1 \mathrm{C} 5$

(a)

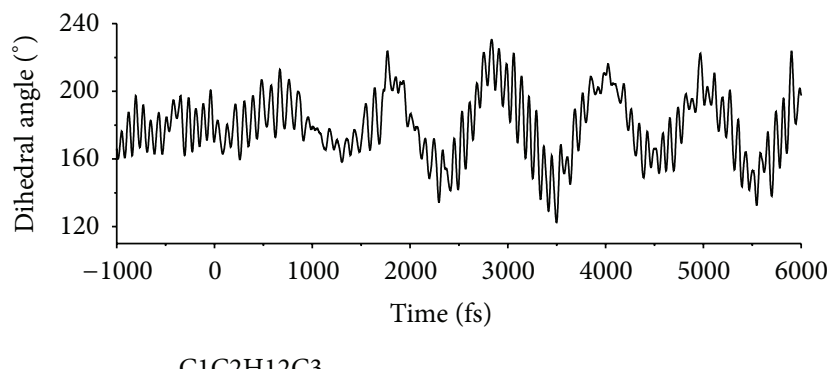

(c)

Figure 4: Time dependence in $\mathrm{BMH}$ of (a) $\mathrm{C} 1 \mathrm{C} 2 \mathrm{C} 3 \mathrm{C} 6$ dihedral angle, (b) $\mathrm{C} 3 \mathrm{C} 2 \mathrm{C} 1 \mathrm{C} 5$ dihedral angle,and (c) $\mathrm{C} 1 \mathrm{C} 2 \mathrm{H} 12 \mathrm{C} 3$ dihedral angle for the trans-to-cis isomerization. All labels are defined in Figure 1.

angles $\mathrm{C} 3 \mathrm{C} 2 \mathrm{C} 1 \mathrm{C} 5$ and $\mathrm{C} 1 \mathrm{C} 2 \mathrm{H} 12 \mathrm{C} 3$ are also displayed in Figure 4. During the whole simulation, $\mathrm{C} 3 \mathrm{C} 2 \mathrm{C} 1 \mathrm{C} 5$ vibrates around $0^{\circ}$. That is, there is no evident rotation around C1$\mathrm{C} 2$ bond. $\mathrm{C} 1 \mathrm{C} 2 \mathrm{H} 12 \mathrm{C} 3$ also does not vary evidently during the whole simulation and keeps on vibrating around $180^{\circ}$, which demonstrates that $\mathrm{H} 12$ atom stays nearly in a plane with atoms $\mathrm{C} 1, \mathrm{C} 2$, and $\mathrm{C} 3$ all the time.

Three bond angles in BMH during the trans-to-cis isomerization are presented in Figure 5. As we can see, during the whole simulation, $\mathrm{C} 1 \mathrm{C} 2 \mathrm{C} 3$ bond angle keeps on vibrating around $125^{\circ}$, while $\mathrm{C} 2 \mathrm{ClC} 5$ bond angle keeps on staying around $121^{\circ}$. C2C $3 \mathrm{~N} 21$ vibrates around $119^{\circ}$ (the optimized $\mathrm{C} 2 \mathrm{C} 3 \mathrm{~N} 21$ value in trans-BMH) before the excitation at $0 \mathrm{fs}$ and then stays around $128^{\circ}$ (the optimized C2C3N21 value in cis-BMH) after the deexcitation at $1740 \mathrm{fs}$.

Time dependence of five bond lengths in BMH is shown in Figures 6 and 7. As shown in Figure 6, after the excitation at $0 \mathrm{fs}, \mathrm{C} 2=\mathrm{C} 3$ bond is weakened, increasing from $1.37 \AA$ to $1.47 \AA$ and then returning to $1.37 \AA$ after the deexcitation at $1740 \mathrm{fs}$. On the other hand, other two bond lengths presented in Figure 6, C1-C2 and C3-N21, are shortened from $1.47 \AA$ to $1.40 \AA$ and from $1.43 \AA$ to $1.37 \AA$ after the excitation at $0 \mathrm{fs}$, respectively. After the deexcitation at $1740 \mathrm{fs}$, both bond angles, $\mathrm{C} 1-\mathrm{C} 2$ and $\mathrm{C} 3-\mathrm{N} 21$, return to their initial values before the excitation. Time dependence of other two carboncarbon bonds, C3-C6 and C1-C4, which are connected with 


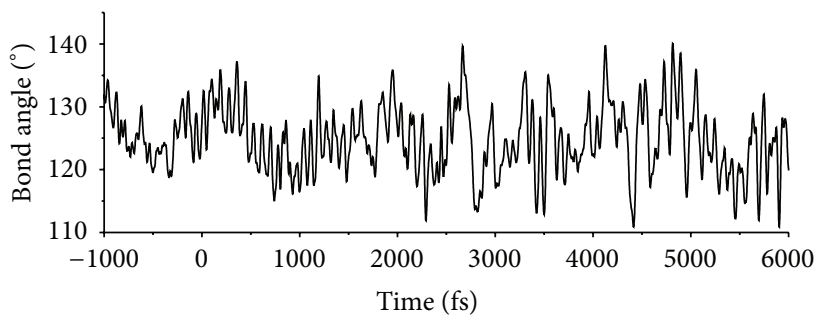

$-\mathrm{C} 1 \mathrm{C} 2 \mathrm{C} 3$

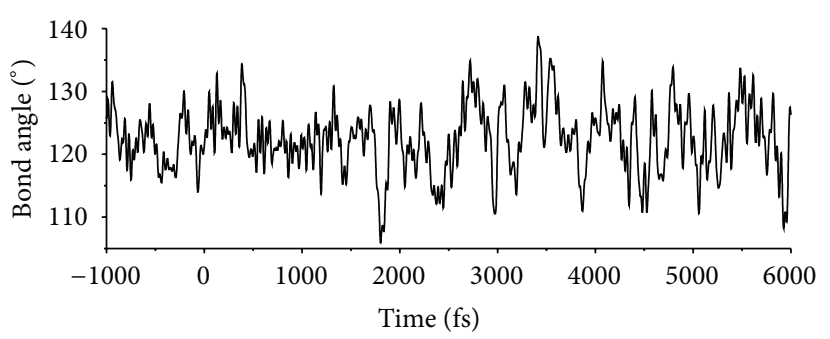

$-\mathrm{C} 2 \mathrm{C} 1 \mathrm{C} 5$

(a)

(b)

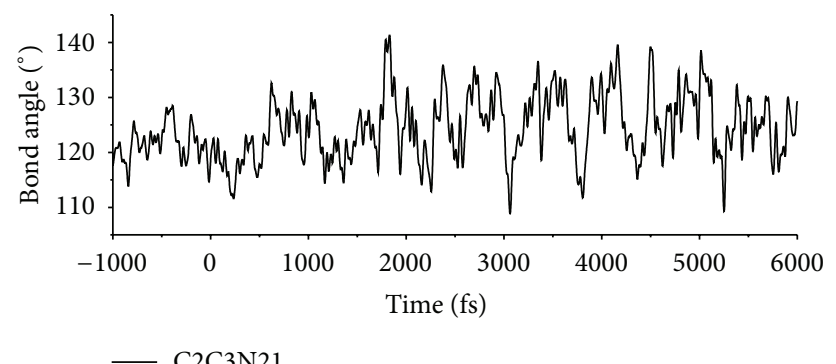

(c)

FIgure 5: Time dependence in BMH of three bond angles: (a) C1C2C3, (b) C2C1C5, and (c) C2C3N21 for the trans-to-cis isomerization. All labels are defined in Figure 1.

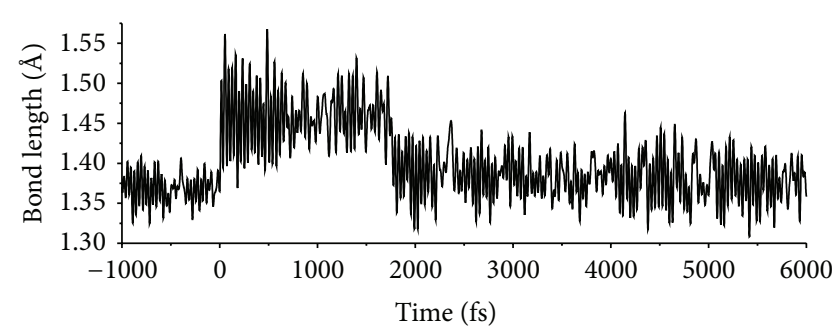

$-\mathrm{C} 2-\mathrm{C} 3$

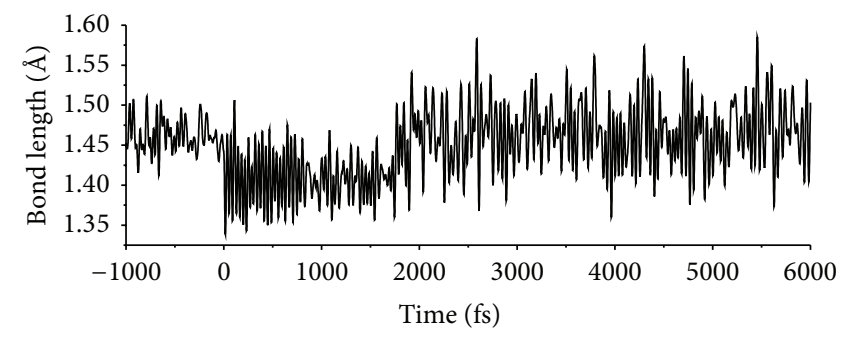

$-\mathrm{C} 1-\mathrm{C} 2$

(a)

(b)

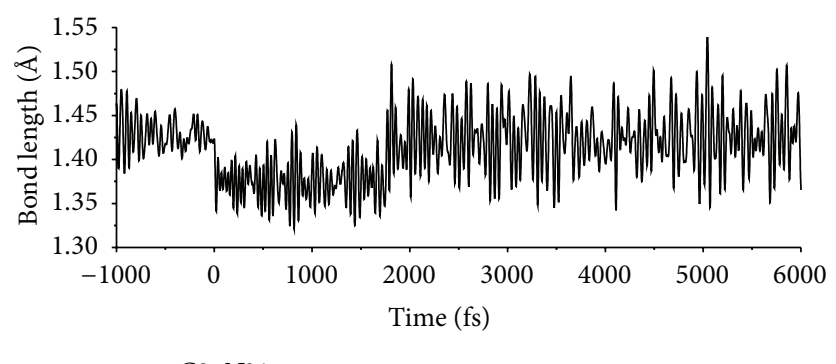

(c)

Figure 6: Time dependence in BMH of (a) bond length C2-C3, (b) bond length C1-C2, and (c) bond length C3-N21 for the trans-to-cis isomerization. All labels are defined in Figure 1.

$\mathrm{C} 2=\mathrm{C} 3$ and $\mathrm{C} 1-\mathrm{C} 4$, respectively, are displayed in Figure 7. As we can see, after the excitation at $0 \mathrm{fs}, \mathrm{C} 3-\mathrm{C} 6$ was also shortened, decreasing from $1.46 \AA$ to $1.43 \AA$, and returning to $1.46 \AA$ after the deexcitation at $1740 \mathrm{fs}$. The $\mathrm{Cl}-\mathrm{C} 4$ bond length increases from $1.41 \AA$ to $1.45 \AA$ at 0 fs and comes back to $1.41 \AA$ after $1740 \mathrm{fs}$.

For the representative trans-to-cis isomerization of $\mathrm{BMH}$ discussed above, lifetime of the $S_{1}$ excited state in 


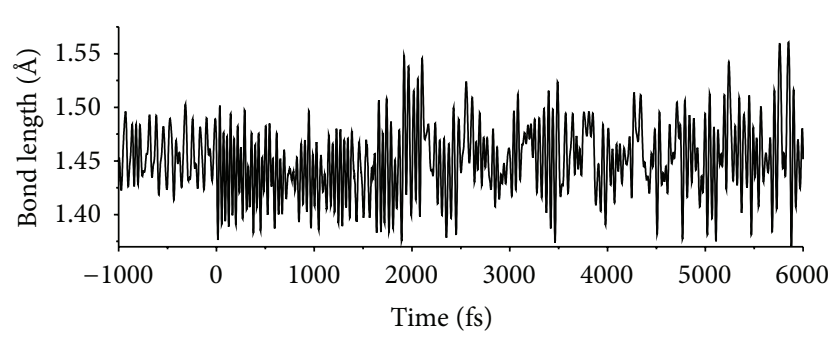

$-\mathrm{C} 3-\mathrm{C} 6$

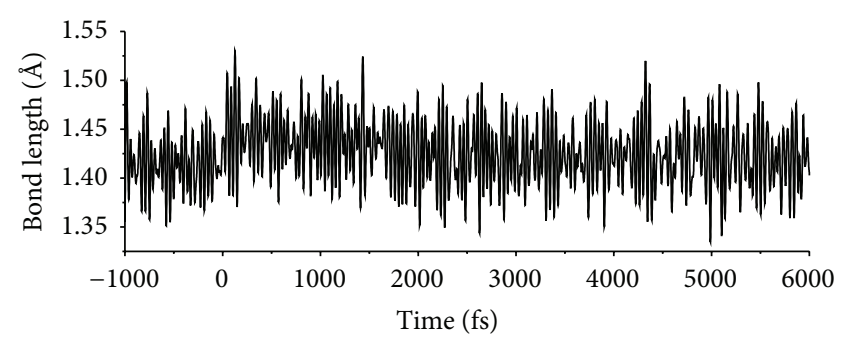

$-\mathrm{C} 1-\mathrm{C} 4$

(a)

(b)

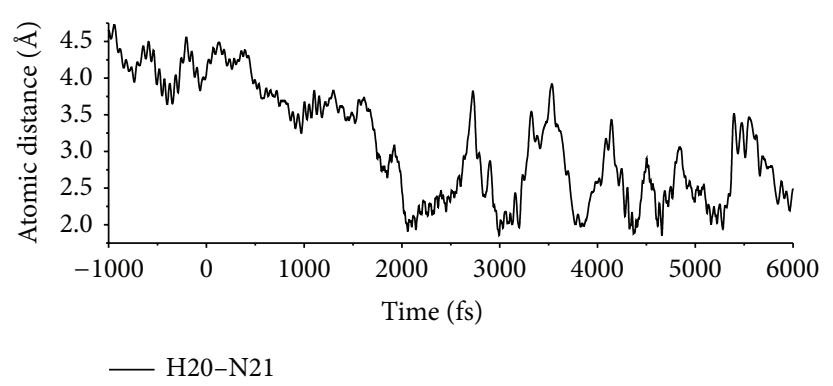

(c)

FIGURE 7: Time dependence in BMH of (a) bond length C3-C6, (b) bond length C1-C4, and (c) atomic distance H20-N21 for the trans-to-cis isomerization. All labels are defined in Figure 1.

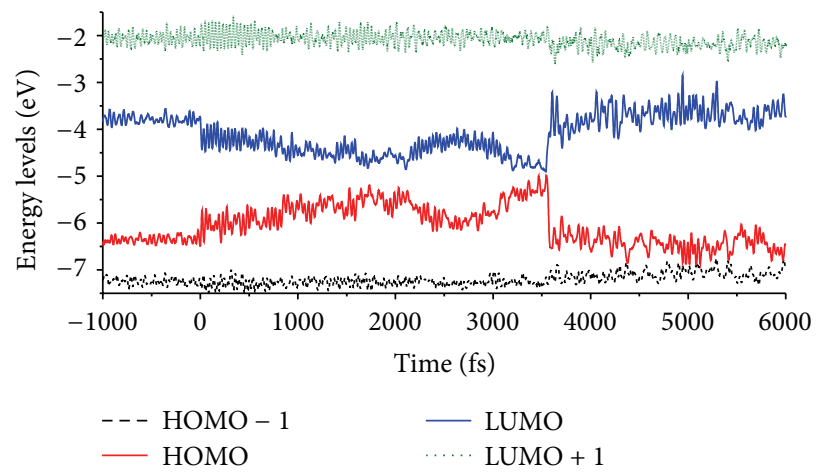

(a)

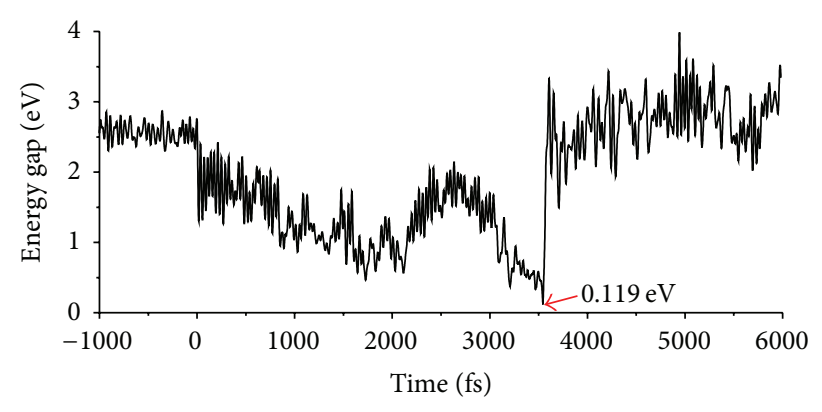

(b)

FIgURE 8: (a) Orbital energies from HOMO - 1 to LUMO + 1 and (b) LUMO-HOMO energy gap in BMH as a function of time for the cis-to-trans isomerization.

trans-BMH is about $1740 \mathrm{fs}$, while the cis geometry is arrived in about 2040 fs. Rotation around C2=C3 bond is the dominant reaction mechanism. Deexcitation occurs near the midpoint of the rotation, due to an avoided crossing near the $S_{1} /$ $S_{0}$ conical intersection.

3.2. cis-to-trans Photoisomerization of BMH. On the basis of 60 simulations, 20 of which did produce cis-to-trans isomerization, we find a quantum yield of 33\% for cis-totrans isomerization of $\mathrm{BMH}$ induced by the excitation to its $S_{1}$ excited state, which is only a little larger than that of transto-cis isomerization of BMH. For the 20 simulations which did produce cis-to-trans isomerization, the average $S_{1}$ lifetime of cis-BMH is about $3100 \mathrm{fs}$. In order to provide the detailed cis-to-trans reaction mechanism, a single representative simulation with a $3545 \mathrm{fs} S_{1}$ lifetime is discussed below.

Time dependence of orbital energies from HOMO - 1 to LUMO + 1 and energy gap between LUMO and HOMO in $\mathrm{BMH}$ during the cis-to-trans photoisomerization are shown in Figure 8. For comparison, the results of ortibal energies and LUMO-HOMO energy gap before the excitation are also displayed in this figure. As we can see, after the excitation at $0 \mathrm{fs}$, only HOMO and LUMO energies are strongly affected by the nuclear motion. The LUMO-HOMO energy gap decreases from $2.7 \mathrm{eV}$ to about $0.5 \mathrm{eV}$ in $2000 \mathrm{fs}$, increases to about $2.0 \mathrm{eV}$ at about $2500 \mathrm{fs}$, and decreases again to the minimum value of $0.119 \mathrm{eV}$ in this simulation at $3543 \mathrm{fs}$. After $3600 \mathrm{fs}$, the LUMO-HOMO energy gap increases to about 


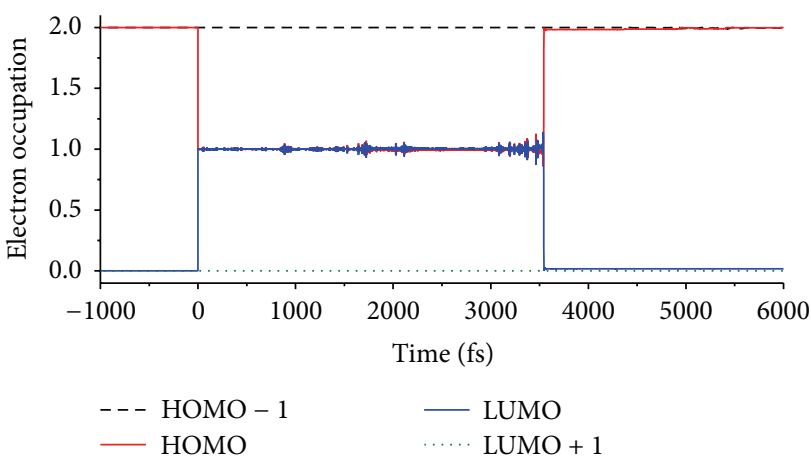

(a)

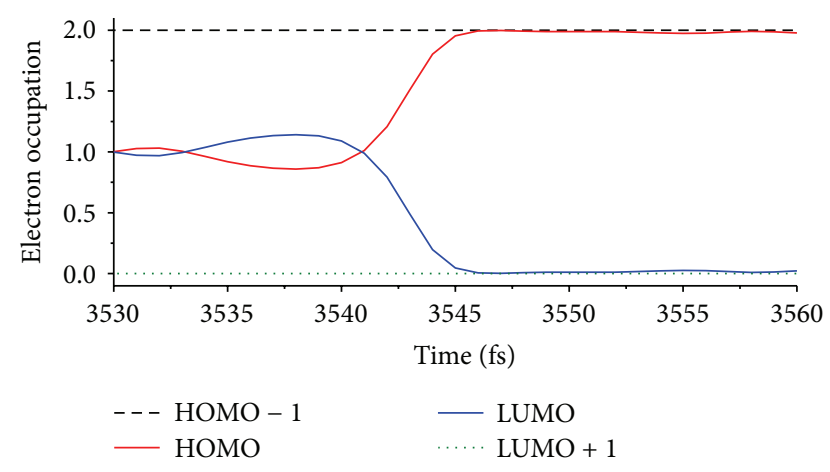

(b)

FIGURE 9: (a) Electron occupancies in BMH from HOMO - 1 to LUMO + 1 for the cis-to-trans isomerization. (b) Details of Figure 9(a) from 3530 to $3560 \mathrm{fs}$.

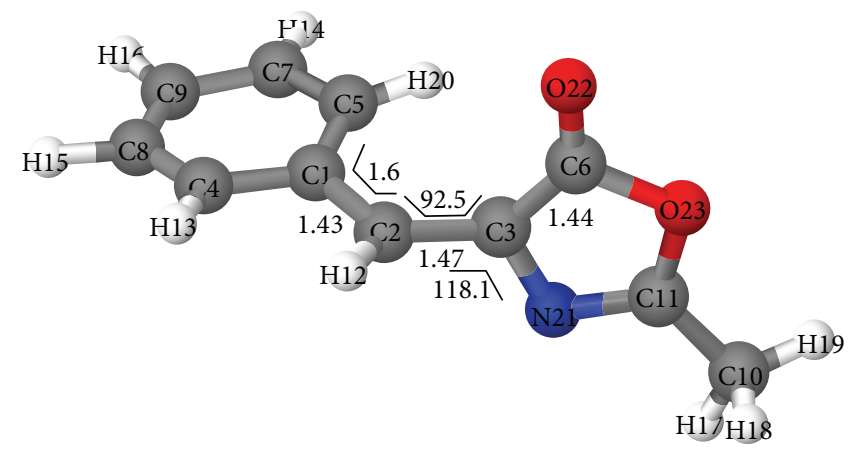

FIGURE 10: Geometry of $\mathrm{BMH}$ at $3543 \mathrm{fs}$ in our cis-to-trans isomerization simulation, which is near a $S_{1} / S_{0}$ conical intersection. Bond lengths are in angstroms, and bond angles and dihedral angles are in degrees.

$2.7 \mathrm{eV}$ and vibrates around this value until the end of this simulation.

Variations of electron occupancies in the orbitals from $\mathrm{HOMO}-1$ to $\mathrm{LUMO}+1$ during the cis-to-trans photoisomerization are displayed in Figure 9. Details of the electron occupancies between 3530 and $3560 \mathrm{fs}$ are also shown in this figure. As we can see, after the excitation at $0 \mathrm{fs}, \mathrm{BMH}$ stays in the first excited state until the deexcitation occurring at $3543 \mathrm{fs}$, which is corresponding to an avoided crossing near the $S_{1} /$ $S_{0}$ conical intersection, as shown in Figure 8.

The geometry of BMH at $3543 \mathrm{fs}$ is displayed in Figure 10. At this point, $\mathrm{C} 1 \mathrm{C} 2 \mathrm{C} 3 \mathrm{C} 6$ dihedral angle is equal to $92.5^{\circ}$, near the midpoint of the rotation. Bond length $\mathrm{C} 2=\mathrm{C} 3$ is equal to $1.47 \AA$, much longer than the ordinary $\mathrm{C}=\mathrm{C}$ bond length. Other geometrical values, such as bond lengths and bond angles, are also presented in this figure.

Variations of geometry during the cis-to-trans photoisomerization of BMH are presented in Figures 11-14. Time dependence of three dihedral angles in $\mathrm{BMH}, \mathrm{C1C} 2 \mathrm{C} 3 \mathrm{C} 6$, $\mathrm{C} 3 \mathrm{C} 2 \mathrm{C} 1 \mathrm{C} 5$, and $\mathrm{C} 1 \mathrm{C} 2 \mathrm{H} 12 \mathrm{C} 3$, is shown in Figure 11. As shown in this figure, after the excitation at $0 \mathrm{fs}$, dihedral angle C1C2C3C6 increases from $180^{\circ}$ to about $240^{\circ}$ in $900 \mathrm{fs}$, stays around $240^{\circ}$ between $900 \mathrm{fs}$ and $2100 \mathrm{fs}$ and then changes the rotation direction, and decreases dramatically from $240^{\circ}$ to $0^{\circ}$. When $\mathrm{BMH}$ arrives at an avoided crossing near the $S_{1} / S_{0}$ conical intersection at $3543 \mathrm{fs}$, the value of C1C2C3C6 reaches $92.5^{\circ}$, as shown in Figure 10. C1C2C3C6 arrives at $0^{\circ}$ (the optimized C1C2C3C6 value in trans-BMH) at $3623 \mathrm{fs}$ and then vibrates around this new value until the end of our simulation. This new $\mathrm{C} 1 \mathrm{C} 2 \mathrm{C} 3 \mathrm{C} 6$ value $\left(0^{\circ}\right)$ can be a demonstration that the molecule arrives at its trans geometry in about 3623 fs. Atomic distance between H20 and N21 presented in Figure 14(c) can be another confirmation for the final trans geometry, which does not vary evidently before 3000 fs but increases continuously from about $2.2 \AA$ to $4.4 \AA$ (the optimized distance between $\mathrm{H} 20$ and N21 in trans-BMH) in subsequent $600 \mathrm{fs}$ and then vibrates around this value until the end of our simulation. As can be seen in Figure 11(b), dihedral angle $\mathrm{C} 3 \mathrm{C} 2 \mathrm{C} 1 \mathrm{C} 5$ stays around $180^{\circ}$ before $\mathrm{BMH}$ returns to its ground state at $3545 \mathrm{fs}$. But due to the energy redistribution among the molecule after deexcitation, $\mathrm{BMH}$ starts and keeps on rotating around C1-C2 bond until the end of our simulation. Similar results have been found in photoisomerization of stilbene and azobenzene [14, 40]. C1C2H12C3 also does not vary evidently during the whole simulation and keeps on vibrating around $180^{\circ}$, which can demonstrate that $\mathrm{H} 12$ atom stays nearly in a plane with atoms $\mathrm{C} 1, \mathrm{C} 2$, and $\mathrm{C} 3$ all the time.

Time variations of three bond angles, C1C2C3, C2C1C5, and C2C3N21, are shown in Figure 12. As we can see, C1C2C3 keeps on vibrating around $125^{\circ}$ during the whole simulation, while $\mathrm{C} 2 \mathrm{C} 1 \mathrm{C} 5$ stays around $120^{\circ}$. For $\mathrm{C} 2 \mathrm{C} 3 \mathrm{~N} 21$, it vibrates 


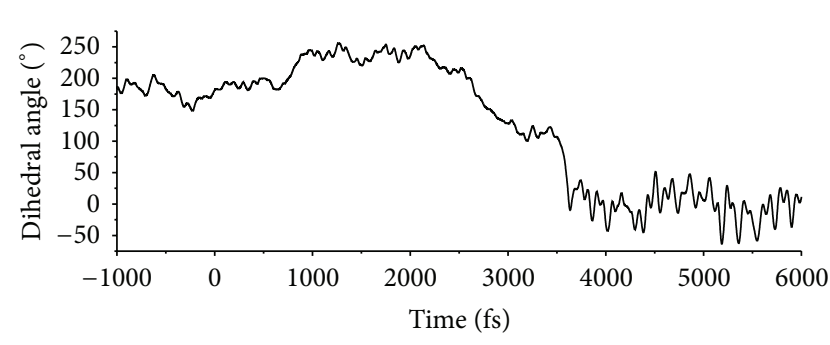

$\mathrm{C} 1 \mathrm{C} 2 \mathrm{C} 3 \mathrm{C} 6$

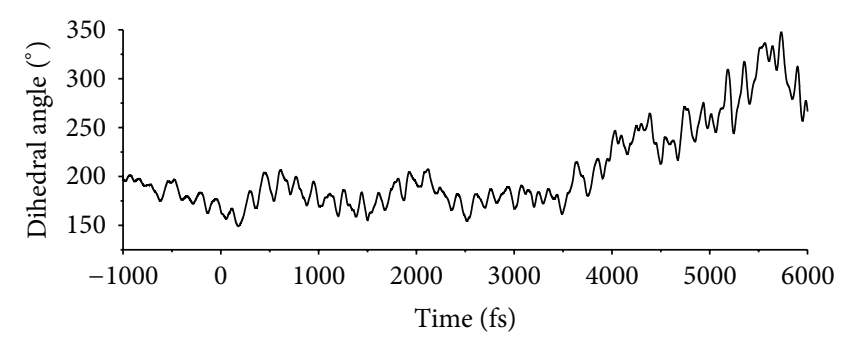

$-\mathrm{C} 3 \mathrm{C} 2 \mathrm{C} 1 \mathrm{C} 5$

(a)

(b)

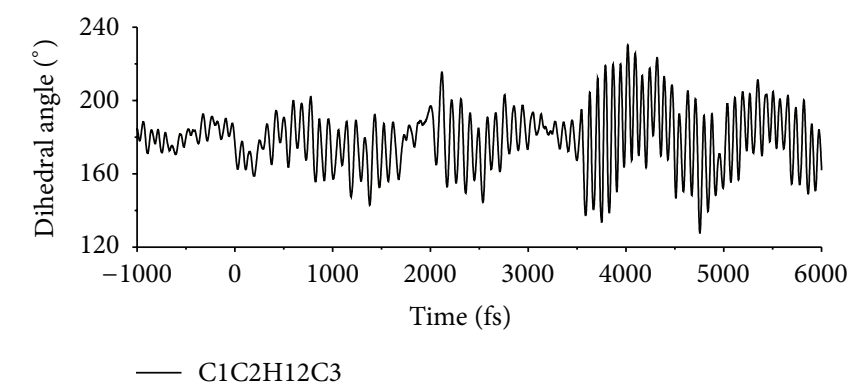

(c)

FIGURE 11: Time dependence in BMH of (a) C1C2C3C6 dihedral angle, (b) C3C2C1C5 dihedral angle, and (c) C1C2H12C3 dihedral angle for the cis-to-trans isomerization. All labels are defined in Figure 1.
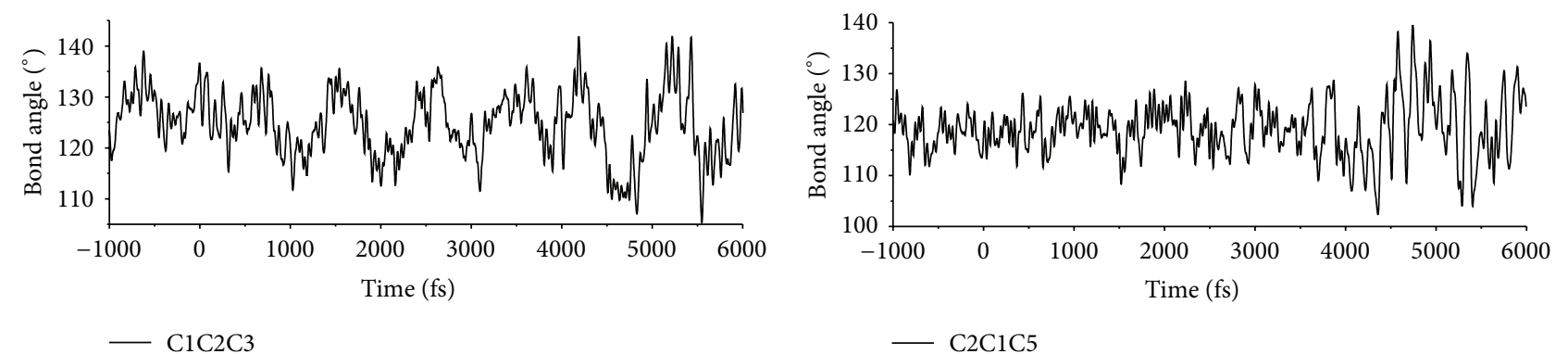

(a)

(b)

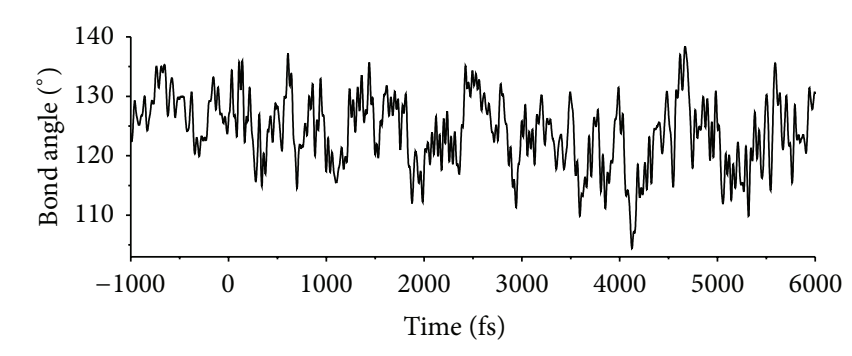

$-\mathrm{C} 2 \mathrm{C} 3 \mathrm{~N} 21$

(c)

FIgURE 12: Time dependence in BMH of three bond angles (a) $\mathrm{C} 1 \mathrm{C} 2 \mathrm{C} 3$, (b) $\mathrm{C} 2 \mathrm{C} 1 \mathrm{C} 5$, and (c) $\mathrm{C} 2 \mathrm{C} 3 \mathrm{~N} 21$ for the cis-to-trans isomerization. All labels are defined in Figure 1.

around $128^{\circ}$ before the excitation at $0 \mathrm{fs}$ and decreases slowly to about $119^{\circ}$ (the optimized value of $\mathrm{C} 2 \mathrm{C} 3 \mathrm{~N} 21$ in trans$\mathrm{BMH}$ ) when deexcitation occurs at $3543 \mathrm{fs}$.

Figure 13 displays the time dependence of three bond lengths in $\mathrm{BMH}$. After the excitation at $0 \mathrm{fs}, \mathrm{C} 2=\mathrm{C} 3$ is weakened, increasing from $1.35 \AA$ to $1.46 \AA$ and returning to $1.35 \AA$ after the deexcitation at $3545 \mathrm{fs}$. Two other bonds shown in Figures 12(a) and 12(b), on the other hand, are shortened after the excitation at $0 \mathrm{fs}$. C1-C2 decreases from $1.46 \AA$ to $1.40 \AA$ after $0 \mathrm{fs}$ and goes back to $1.46 \AA$ after $3545 \mathrm{fs}$. 


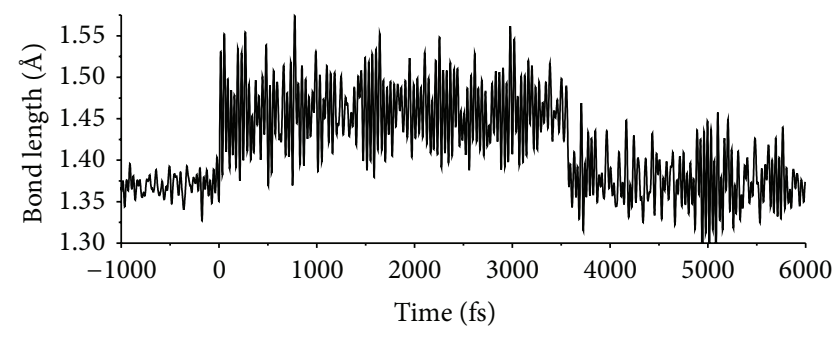

$-\mathrm{C} 2-\mathrm{C} 3$

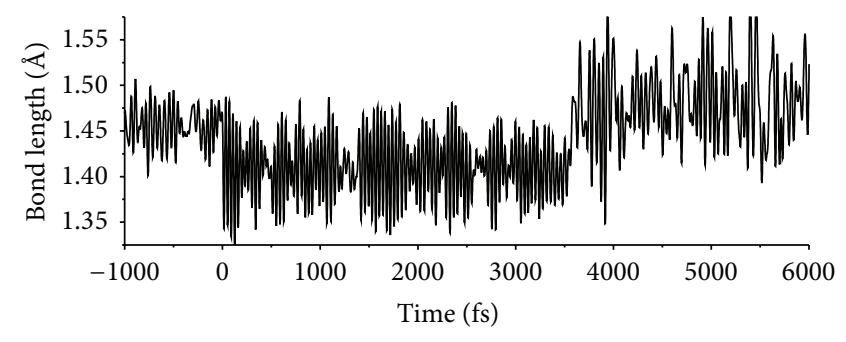

$-\mathrm{C} 1-\mathrm{C} 2$

(b)

(a)

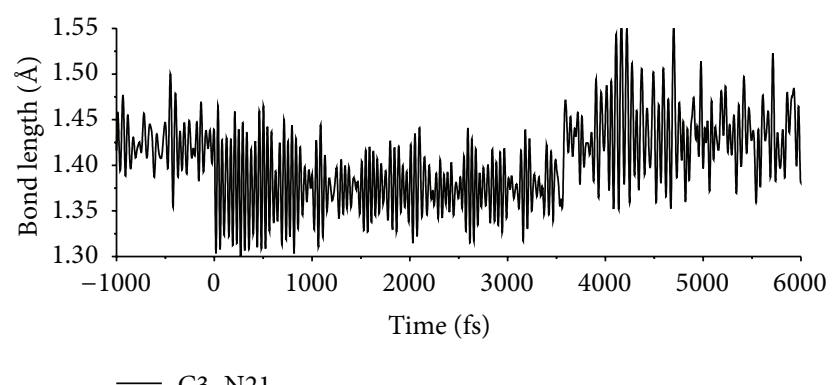

(c)

FIGURE 13: Time dependence in BMH of bond lengths (a) C2-C3, (b) C1-C2, and (c) C3-N21 for the cis-to-trans isomerization. All labels are defined in Figure 1.

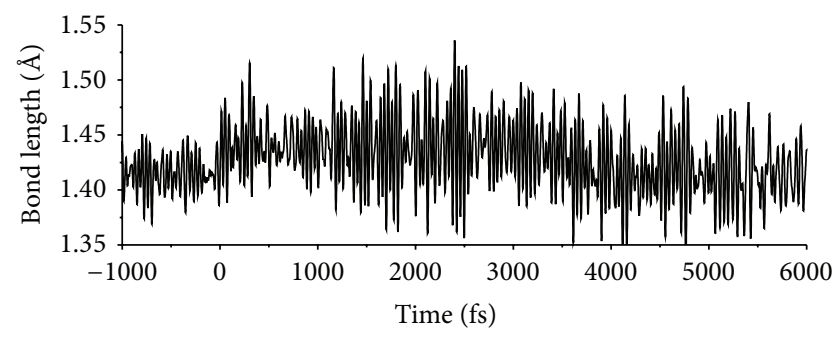

- C1-C4

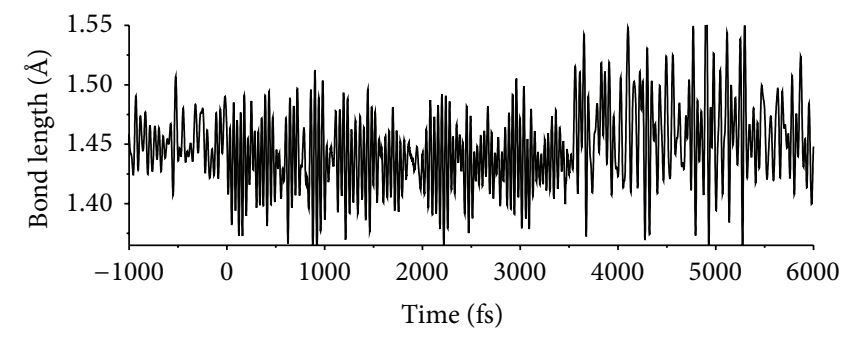

- C3-C6

(a)

(b)

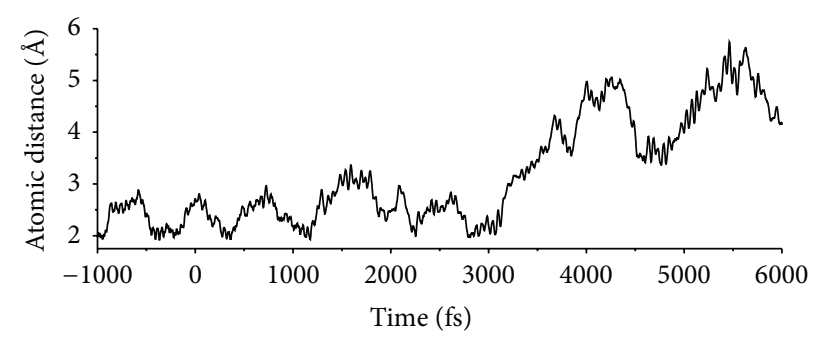

- H20-N21

(c)

Figure 14: Time dependence in BMH of (a) bond length C3-C6, (b) bond length C1-C4, and (c) atomic distance H20-N21 for the cis-to-trans isomerization. All labels are defined in Figure 1.

C3-N21 decreases from $1.43 \AA$ to $1.38 \AA$ after the excitation and returns to its initial value after the deexcitation. Bond lengths $\mathrm{C} 1-\mathrm{C} 4$ and $\mathrm{C} 3-\mathrm{C} 6$, as shown in Figure 14, are also affected by the excitation and deexcitation. C1-C4 increases from $1.41 \AA$ to $1.45 \AA$ after 0 fs and returns to its initial value after deexcitation. Bond length of C3-C6 decreases from $1.46 \AA$ to $1.43 \AA$ after the excitation and then returns to its initial value $1.46 \AA$ after the deexcitation at $3545 \mathrm{fs}$. 


\section{Conclusions}

With density-functional-based nonadiabatic molecular dynamics simulations, trans-to-cis and cis-to-trans photoisomerizations of a green fluorescent protein chromophore based molecule 4-benzylidene-2-methyloxazol-5(4H)-one $(\mathrm{BMH})$ induced by the excitation to its $S_{1}$ excited state were performed. We find a quantum yield of $32 \%$ for the trans-tocis photoisomerization of $\mathrm{BMH}$ and a quantum yield of $33 \%$ for its cis-to-trans photoisomerization. In those simulations that did produce trans-to-cis isomerization, the range of calculated $S_{1}$ lifetimes was 700-4000 fs, with a mean value of $1450 \mathrm{fs}$. For the finished cis-to-trans isomerization, the range of calculated $S_{1}$ lifetimes was $1200-7000 \mathrm{fs}$, with a mean value of $3100 \mathrm{fs}$. The $S_{1}$ lifetime of cis-BMH is much larger than that of trans-BMH, agreeing well with the experimental result [27].

For the simulation shown in detail, lifetimes of the trans$\mathrm{BMH}$ and cis-BMH are $1740 \mathrm{fs}$ and $3545 \mathrm{fs}$, respectively. The whole trans-to-cis isomerization is finished in about $2040 \mathrm{fs}$, while whole time needed for cis-to-trans isomerization is about $3623 \mathrm{fs}$. For both photoisomerizations, rotation around the central $\mathrm{C} 2=\mathrm{C} 3$ bond is the dominant reaction mechanism; deexcitation occurs at an avoided crossing near the $S_{1} / S_{0}$ conical intersection, which is near the midpoint of the rotation.

\section{Conflict of Interests}

The authors declare that there is no conflict of interests regarding the publication of this paper.

\section{Acknowledgments}

This work was supported by the Natural Science Foundation of China (Grants 21203144, 11074199, and 11174233), Doctoral Fund of Ministry of Education of China (Grant 20120201120056), and the Fundamental Research Funds for the Central Universities.

\section{References}

[1] D. H. Waldeck, "Photoisomerization dynamics of stilbenes," Chemical Reviews, vol. 91, no. 3, pp. 415-438, 1991.

[2] T. Baumert, T. Frohnmeyer, B. Kiefer et al., "Femtosecond transition state dynamics of cis-stilbene," Applied Physics B: Lasers and Optics, vol. 72, no. 1, pp. 105-108, 2001.

[3] W. Fuß, C. Kosmidis, W. E. Schmid, and S. A. Trushin, "The photochemical cis-trans isomerization of free stilbene molecules follows a hula-twist pathway," Angewandte Chemie, vol. 43, no. 32, pp. 4178-4182, 2004.

[4] Y. Ishibashi, M. Murakami, H. Miyasaka, S. Kobatake, M. Irie, and Y. Yokoyama, "Laser multiphoton-gated photochromic reaction of a fulgide derivative," Journal of Physical Chemistry C, vol. 111, no. 6, pp. 2730-2737, 2007.

[5] T. Cordes, S. Malkmus, J. A. DiGirolamo et al., "Accelerated and efficient photochemistry from higher excited electronic states in fulgide molecules," The Journal of Physical Chemistry A, vol. 112, no. 51, pp. 13364-13371, 2008.
[6] F. Renth, R. Siewertsen, and F. Temps, "Enhanced photoswitching and ultrafast dynamics in structurally modified photochromic fulgides," International Reviews in Physical Chemistry, vol. 32, no. 1, pp. 1-38, 2013.

[7] M. Takeshita and M. Irie, "Photoresponsive tweezers for alkali metal ions. Photochromic diarylethenes having two crown ether moieties," Journal of Organic Chemistry, vol. 63, no. 19, pp. 6643-6649, 1998.

[8] S. F. Yan, V. N. Belov, M. L. Bossi, and S. W. Hell, "Switchable fluorescent and solvatochromic molecular probes based on 4-amino-N-methylphthalimide and a photochromic diarylethene," European Journal of Organic Chemistry, vol. 2008, no. 15, pp. 2531-2538, 2008.

[9] Y. Li and Q. Li, "Photochemically reversible and thermally stable axially chiral diarylethene switches," Organic Letters, vol. 14, no. 17, pp. 4362-4365, 2012.

[10] I. K. Lednev, T.-Q. Ye, L. C. Abbott, R. E. Hester, and J. N. Moore, "Photoisomerization of a capped azobenzene in solution probed by ultrafast time-resolved electronic absorption spectroscopy," The Journal of Physical Chemistry A, vol. 102, no. 46, pp. 91619166, 1998.

[11] T. Fujino and T. Tahara, "Picosecond time-resolved Raman study of trans-azobenzene," Journal of Physical Chemistry A, vol. 104, no. 18, pp. 4203-4210, 2000.

[12] H. Satzger, S. Spörlein, C. Root, J. Wachtveitl, W. Zinth, and P. Gilch, "Fluorescence spectra of trans- and cis-azobenzene: emission from the Franck-Condon state," Chemical Physics Letters, vol. 372, no. 1-2, pp. 216-223, 2003.

[13] I. Conti, M. Garavelli, and G. Orlandi, "The different photoisomerization efficiency of azobenzene in the lowest $\mathrm{n} \pi^{*}$ and $\pi \pi^{*}$ singlets: the role of a phantom state," Journal of the American Chemical Society, vol. 130, no. 15, pp. 5216-5230, 2008.

[14] C.-W. Jiang, R.-H. Xie, F.-L. Li, and R. E. Allen, "Comparative studies of the trans-Cis photoisomerizations of azobenzene and a bridged azobenzene," Journal of Physical Chemistry A, vol. 115, no. 3, pp. 244-249, 2011.

[15] H.-H. Liu, X. Zhang, Z. Gao, and Y. Chen, "Photoconversion of a protonated diarylethene derivative," Journal of Physical Chemistry A, vol. 116, no. 40, pp. 9900-9903, 2012.

[16] G. Haberhauer and C. Kaliweit, "A bridged azobenzene derivative as a reversible, light-induced chirality switch," Angewandte Chemie, vol. 49, no. 13, pp. 2418-2421, 2010.

[17] I. K. Lednev, T.-Q. Ye, P. Matousek et al., "Femtosecond timeresolved UV-visible absorption spectroscopy of trans-azobenzene: dependence on excitation wavelength," Chemical Physics Letters, vol. 290, no. 1-3, pp. 68-74, 1998.

[18] T. Pancur, F. Renth, F. Temps et al., "Femtosecond fluorescence up-conversion spectroscopy of a rotation-restricted azobenzene after excitation to the S1 state," Physical Chemistry Chemical Physics, vol. 7, no. 9, pp. 1985-1989, 2005.

[19] R. Siewertsen, H. Neumann, B. Buchheim-Stehn et al., "Highly efficient reversible Z-E photoisomerization of a bridged azobenzene with visible light through resolved S1(npi*) absorption bands," Journal of the American Chemical Society, vol. 131, no. 43, pp. 15594-15595, 2009.

[20] M. Chalfie, Y. Tu, G. Euskirchen, W. W. Ward, and D. C. Prasher, "Green fluorescent protein as a marker for gene expression," Science, vol. 263, no. 5148, pp. 802-805, 1994.

[21] V. Voliani, R. Bizzarri, R. Nifosì et al., "Cis-trans photoisomerization of fluorescent-protein chromophores," The Journal of Physical Chemistry B, vol. 112, no. 34, pp. 10714-10722, 2008. 
[22] S. Rafiq, B. K. Rajbongshi, N. N. Nair, P. Sen, and G. Ramanathan, "Excited state relaxation dynamics of model green fluorescent protein chromophore analogs: Evidence for cistrans isomerism," Journal of Physical Chemistry A, vol. 115, no. 47, pp. 13733-13742, 2011.

[23] J.-S. Yang, G.-J. Huang, Y.-H. Liu, and S.-M. Peng, "Photoisomerization of the green fluorescence protein chromophore and the meta- and para-amino analogues," Chemical Communications, vol. 2008, no. 11, pp. 1344-1346, 2008.

[24] P. Naumov, J. Kowalik, K. M. Solntsev et al., “Topochemistry and photomechanical effects in crystals of green fluorescent protein-like chromophores: Effects of hydrogen bonding and crystal packing," Journal of the American Chemical Society, vol. 132, no. 16, pp. 5845-5857, 2010.

[25] X. He, A. F. Bell, and P. J. Tonge, "Synthesis and spectroscopic studies of model red fluorescent protein chromophores," Organic Letters, vol. 4, no. 9, pp. 1523-1526, 2002.

[26] A. Kikuchi, E. Fukumura, S. Karasawa, H. Mizuno, A. Miyawaki, and Y. Shiro, "Structural characterization of a thiazoline-containing chromophore in an orange fluorescent protein, monomeric kusabira orange," Biochemistry, vol. 47, no. 44, pp. 11573-11580, 2008.

[27] M. Blanco-Lomas, P. J. Campos, and D. Sampedro, "Benzylidene-oxazolones as molecular photoswitches," Organic Letters, vol. 14, no. 17, pp. 4334-4337, 2012.

[28] Y. Dou, B. R. Torralva, and R. E. Allen, "Semiclassical electronradiation-ion dynamics (SERID) and cis-trans photoisomerization of butadiene," Journal of Modern Optics, vol. 50, no. 15-17, pp. 2615-2643, 2003.

[29] R. E. Allen, T. Dumitrica, and B. Torralva, "Electronic and structural response of materials to fast intense laser pulses," in Ultrafast Physical Processes in Semiconductors, K. T. Tsen, Ed., chapter 7, Academic Press, New York, NY, USA, 2001.

[30] R. E. Allen, "Electron-ion dynamics: a technique for simulating both electronic transitions and ionic motion in molecules and materials," Physical Review B, vol. 50, no. 24, pp. 18629-18632, 1994.

[31] R. E. Allen, "Coupling of electrons to the electromagnetic field in a localized basis," Physical Review B, vol. 78, no. 6, Article ID 064305, 2008.

[32] R. E. Allen, T. Dumitrică, and B. Torralva, Ultrafast Physical Processes in Semiconductors, chapter 7, Academic Press, New York, NY, USA, 2001, edited by K. T. Tsen.

[33] D. Porezag, T. Frauenheim, T. Köhler, G. Seifert, and R. Kaschner, "Construction of tight-binding-like potentials on the basis of density-functional theory: application to carbon," Physical Review B, vol. 51, no. 19, pp. 12947-12957, 1995.

[34] G. Seifert, D. Porezag, and T. Frauenheim, "Calculations of molecules, clusters, and solids with a simplified LCAO-DFTLDA scheme," International Journal of Quantum Chemistry, vol. 58, no. 2, pp. 185-192, 1996.

[35] Y. Dou and R. E. Allen, "Detailed dynamics of a complex photochemical reaction: Cis-trans photoisomerization of stilbene," The Journal of Chemical Physics, vol. 119, no. 20, pp. 1065810666, 2003.

[36] Y. Dou, B. R. Torralva, and R. E. Allen, "Interplay of electronic and nuclear degrees of freedom in a femtosecond-scale photochemical reaction," Chemical Physics Letters, vol. 392, no. 4-6, pp. 352-357, 2004.

[37] P. Sauer and R. E. Allen, "Dynamics of the photoinduced ring-opening of stilbene, a prototypical diarylethene," Chemical Physics Letters, vol. 434, no. 4-6, pp. 260-264, 2007.
[38] P. Sauer and R. E. Allen, "Influence of laser pulse parameters on dynamical processes during azobenzene photoisomerization," Journal of Physical Chemistry A, vol. 112, no. 44, pp. 11142-11152, 2008.

[39] C.-W. Jiang, R.-H. Xie, F.-L. Li, and R. E. Allen, "Photocyclization of trans-stilbene induced by an ultrafast laser pulse," Chemical Physics Letters, vol. 487, no. 4-6, pp. 177-182, 2010.

[40] C. Jiang, R. Xie, F. Li, and R. E. Allen, "Trans-to-cis isomerization of stilbene following an ultrafast laser pulse," Chemical Physics Letters, vol. 474, no. 4-6, pp. 263-267, 2009.

[41] C.-W. Jiang, R.-H. Xie, F.-L. Li, and R. E. Allen, "Ultrafast cisto-trans photoisomerization of a bridged azobenzene through $\mathrm{n} \pi$ excitation: rotational pathway is not restricted," Chemical Physics Letters, vol. 521, pp. 107-112, 2012.

[42] Y. Dou, Y. Lei, A. Li et al., "Detailed dynamics of the photodissociation of cyclobutane," The Journal of Physical Chemistry A, vol. 111, no. 6, pp. 1133-1137, 2007.

[43] W. Zhang, S. Yuan, A. Li, Y. Dou, J. Zhao, and W. Fang, "Photoinduced thymine dimerization studied by semiclassical dynamics simulation," Journal of Physical Chemistry C, vol. 114, no. 12, pp. 5594-5601, 2010.

[44] S. Yuan, W. Zhang, L. Liu, Y. Dou, W. Fang, and G. V. Lo, "Detailed mechanism for photoinduced cytosine dimerization: a semiclassical dynamics simulation," Journal of Physical Chemistry A, vol. 115, no. 46, pp. 13291-13297, 2011.

[45] E. Teller, "The crossing of potential surfaces," The Journal of Physical Chemistry, vol. 41, no. 1, pp. 109-116, 1937.

[46] M. Baer, Beyond Born-Oppenheimer: Electronic Nonadiabatic Coupling Terms and Conical Intersections, Wiley-Interscience, Hoboken, NJ, USA, 2006.

[47] C. Nonnenberg, H. Gaub, and I. Frank, "First-principles simulation of the photoreaction of a capped azobenzene: the rotational pathway is feasible," ChemPhysChem, vol. 7, no. 7, pp. 1455-1461, 2006.

[48] Y. Norikane and N. Tamaoki, "Photochemical and thermal cis/ trans isomerization of cyclic and noncyclic azobenzene dimers: effect of a cyclic structure on isomerization," European Journal of Organic Chemistry, no. 5, pp. 1296-1302, 2006.

[49] M. J. Frisch, G. W. Trucks, H. B. Schlegel et al., GAUSSIAN, Inc., Wallingford, CT, 2004. 

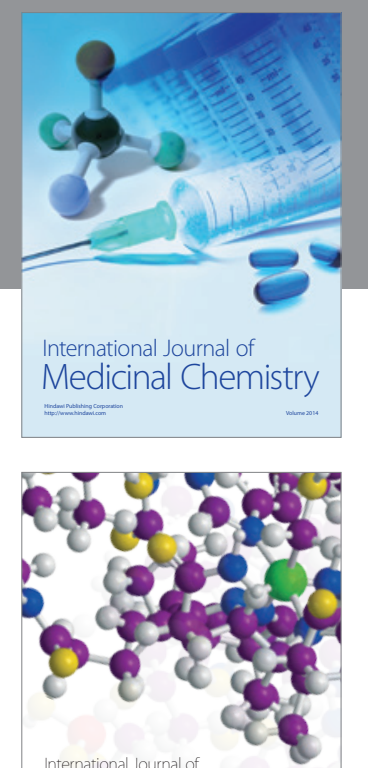

\section{Carbohydrate} Chemistry

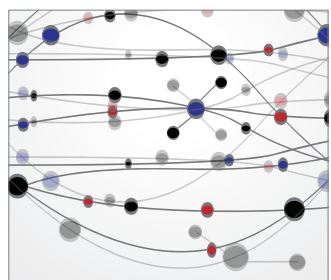

The Scientific World Journal
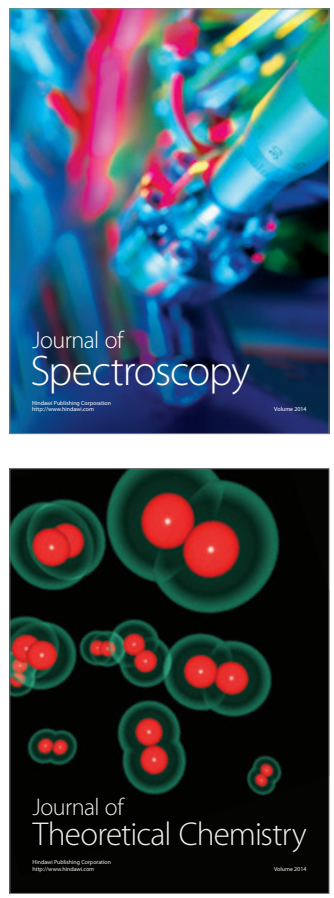
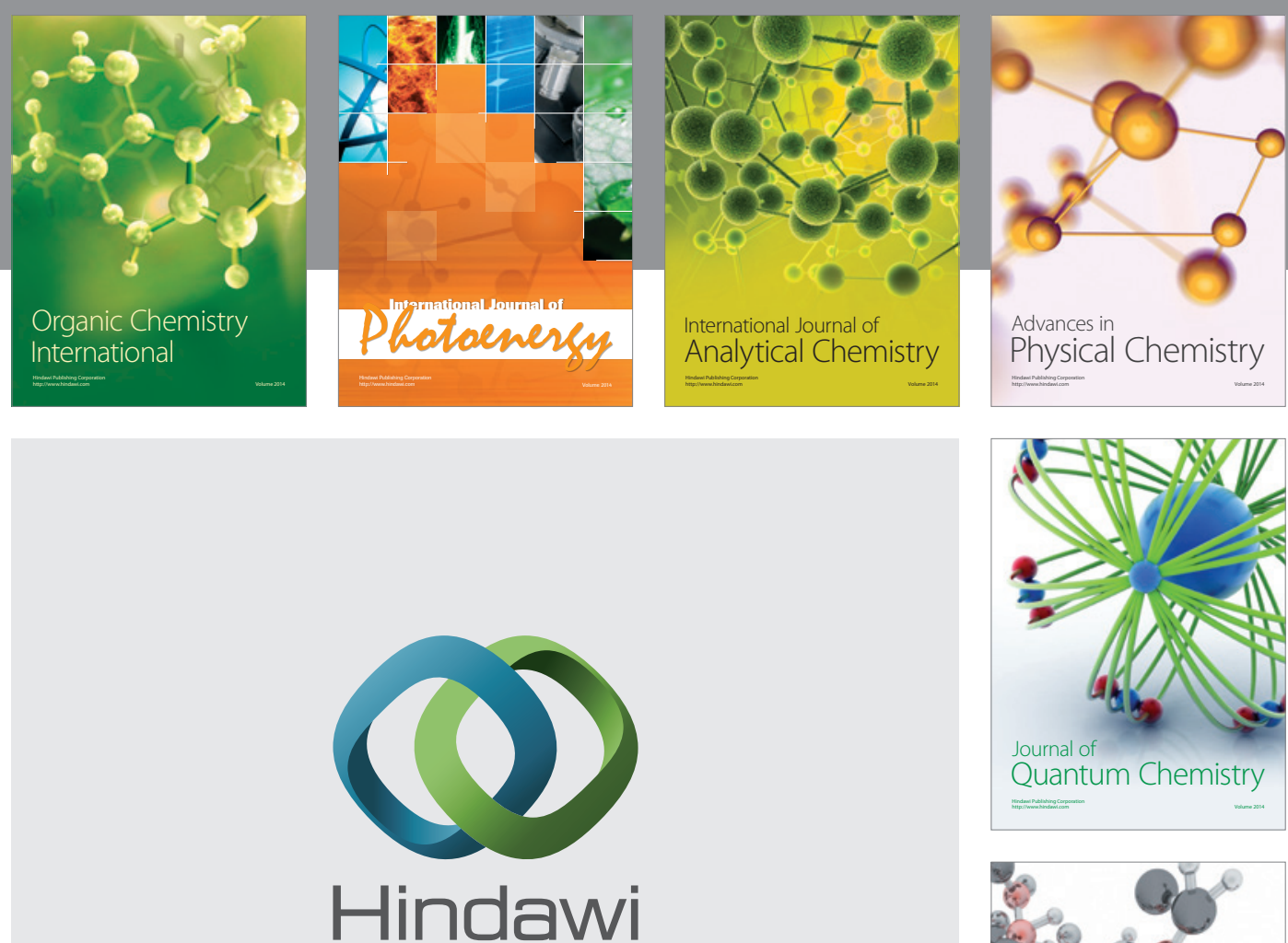

Submit your manuscripts at

http://www.hindawi.com

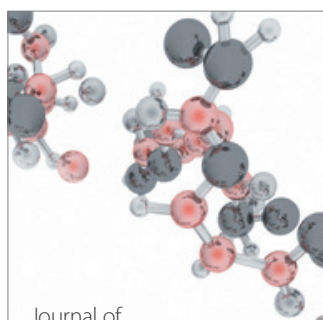

Analytical Methods

in Chemistry

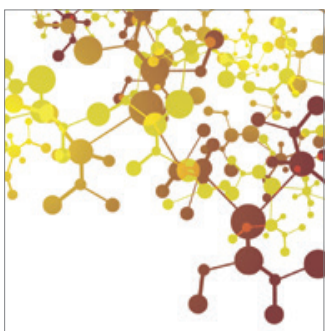

Journal of

Applied Chemistry

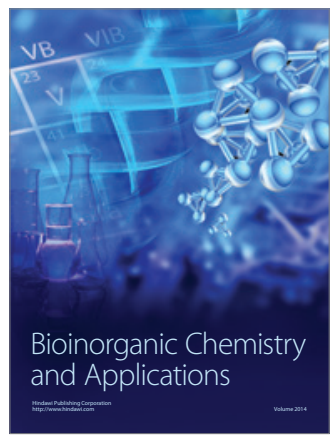

Inorganic Chemistry
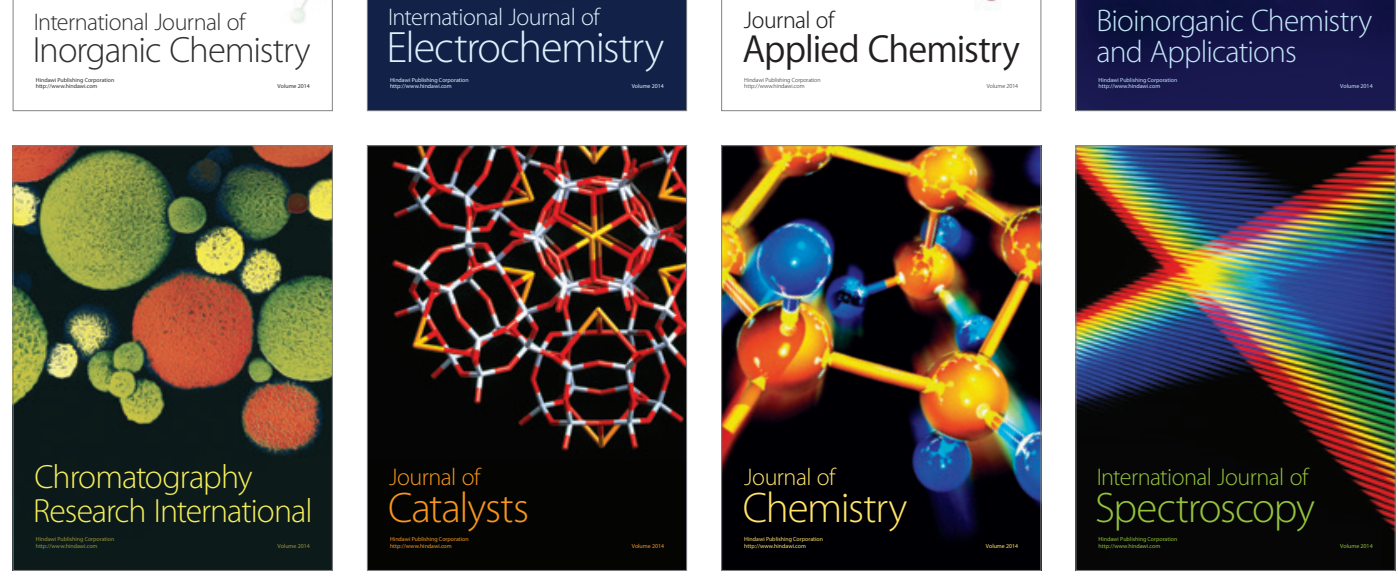